\title{
Diagnostic performance of various cephalometric parameters for the assessment of vertical growth pattern
}

\author{
Maheen Ahmed'1, Attiya Shaikh², Mubassar Fida ${ }^{3}$
}

DOI: http://dx.doi.org/10.1590/2177-6709.21.4.041-049.oar

\begin{abstract}
Introduction: Multiple cephalometric analyses are used to diagnose vertical skeletal facial discrepancy. A multitude of times, these parameters show conflicting results, and a specific diagnosis is hard to reach. Objective: Hence, this study aimed to identify the skeletal analysis that performs best for the identification of vertical skeletal pattern in borderline cases. Methods: The sample consisted of 161 subjects (71 males and 90 females; mean age $=23.6 \pm 4.6$ years). Y-axis, Sella-Nasion to mandibular plane angle (SN.MP), maxillary plane to mandibular plane angle (MMA), Sella-Nasion to Gonion-Gnathion angle (SN.GoGn), Frankfort to mandibular plane angle (FMA), R-angle and facial height ratio (LAFH.TAFH) were used to evaluate vertical growth pattern on lateral cephalograms. The subjects were divided into three groups (hypodivergent, normodivergent and hyperdivergent groups), as indicated by the diagnostic results of the majority of parameters. Kappa statistics was applied to compare the diagnostic accuracy of various analyses. To further validate the results, sensitivity and positive predictive values (PPV) for each parameter were also calculated. Results: SN.GoGn showed a substantial interclass agreement $(\mathrm{k}=0.850)$. In the hypodivergent group, MMA showed the highest sensitivity (0.934), whereas FMA showed the highest PPV (0.964). In the normodivergent group, FMA showed the highest sensitivity (0.909) and SN.GoGn had the highest PPV (0.903). SN.GoGn showed the highest sensitivity (0.980) and PPV (0.87) in the hyperdivergent group. Conclusions: SN.GoGn and FMA were found to be the most reliable indicators, whereas LAFH.TAFH is the least reliable indicator in assessing facial vertical growth pattern. Hence, the cephalometric analyses may be limited to fewer analyses of higher diagnostic performance.
\end{abstract}

Keywords: Divergence. Cephalometry. Vertical dimension.

Introdução: diferentes análises cefalométricas são utilizadas para se diagnosticar a discrepância esquelética vertical da face. Muitas vezes, essas análises revelam resultados conflitantes, tornado complicado obter um diagnóstico preciso. Objetivo: o objetivo do presente estudo foi identificar a melhor análise esquelética para identificação do padrão esquelético vertical em casos limítrofes. Métodos: a amostra consistiu em 161 indivíduos (71 homens e 90 mulheres, com idade média de 23,6 4 4,6 anos). Para avaliar o padrão de crescimento vertical em telerradiografias de perfil, foram utilizados: o eixo Y, o ângulo formado entre a linha sela-násio e o plano mandibular (SN.MP), ângulo formado pelos planos maxilar e mandibular (MMA), ângulo formado pelas linhas sela-násio e gônio-gnátio (SN.GoGn), ângulo formado pelo plano de Frankfort e o plano mandibular (FMA), o ângulo R, e a proporção de altura facial (AFAI.AFAT). Os indivíduos foram divididos em três grupos (hipodivergente, neutro e hiperdivergente), em acordo com os resultados diagnósticos da maioria dessas medidas. A análise estatística Kappa foi empregada para comparar a precisão diagnóstica das diferentes análises. Para uma validação adicional dos resultados, também foram calculados, para cada medida, a sensibilidade e os valores preditivos positivos (VPP). Resultados: o SN.GoGn apresentou um valor alto de concordância interclasses $(\mathrm{k}=0,850)$. No grupo hipodivergente, o MMA apresentou a maior sensibilidade (0,934), enquanto o FMA apresentou o VPP mais alto (0,964). No grupo neutro, o FMA apresentou a maior sensibilidade $(0,909)$, enquanto o SN.GoGn apresentou o VPP mais alto (0,903). No grupo hiperdivergente, o SN.GoGn apresentou a maior sensibilidade (0,980) e o valor mais alto de VPP $(0,87)$. Conclusões: constatou-se que, para avaliação do padrão de crescimento facial vertical, o SN.GoGn e o FMA foram os indicadores mais confiáveis, enquanto o AFAI.AFAT foi o indicador menos confiável. Sendo assim, a análise cefalométrica pode se limitar às análises com maior desempenho diagnóstico.

Palavras-chave: Divergência. Cefalometria. Dimensão vertical.

${ }^{1}$ Resident in Orthodontics, The Aga Khan University Hospital, Section of Dentistry, Department of Surgery, Karachi, Pakistan.

${ }^{2}$ Consultant Orthodontist/Assistant Professor, Program Coordinator Orthodontics Residency Program, The Aga Khan University Hospital, Section of Dentistry, Department of Surgery, Karachi, Pakistan.

${ }^{3}$ Consultant Orthodontist/Associate Professor, Program Director Orthodontics Residency Program, The Aga Khan University Hospital, Section of Dentistry, Department of Surgery, Karachi, Pakistan.

Contact address: Maheen Ahmed

The Aga Khan University Hospital, P.O Box 3500, Stadium Road, Karachi 74800, Pakistan - Email: a_maheen01@hotmail.com
How to cite this article: Ahmed M, Shaikh A, Fida M. Diagnostic performance of various cephalometric parameters for the assessment of vertical growth pattern. Dental Press J Orthod. 2016 Jul-Aug;21(4):41-9.

DOI: http://dx.doi.org/10.1590/2177-6709.21.4.041-049.oar

Submitted: August 09, 2015 - Revised and accepted: December 17, 2015

» The authors report no commercial, proprietary or financial interest in the products or companies described in this article. 


\section{INTRODUCTION}

Facial vertical growth pattern plays a vital role in achieving facial balance. ${ }^{1}$ Variations in vertical growth are common and have certain orthodontic implications. A long or a short face may be due to abnormal hard or soft tissues that form the face. Growth excess in the vertical dimension may result in gingival smile, incompetent lips and a long face. ${ }^{2}$ On the contrary, a deficiency in vertical growth may lead to inadequate display of incisors, overclosure of lips and a short face. ${ }^{3}$ Both facial types are considered unesthetic and are included in the orthodontic problem list. Treatment of such problems is usually carried out by functional jaw orthopedics in growing patients and by orthognathic surgery in adults. The success of a treatment plan in Orthodontics is not only dependent on understanding where growth occurs, but also when it ends. ${ }^{4}$ As the vertical component of growth is the last to end, failure to control it may lead to complex treatment, compromised results and relapse after treatment. ${ }^{5,6}$ This mandates a thorough assessment and an accurate diagnostic evaluation of such discrepancies in the vertical facial pattern to ensure treatment success.

Lateral cephalometry has made the assessment of vertical skeletal problems an easy and accurate process. Downs, ${ }^{7}$ in 1948, used Frankfort horizontal (FH) plane as the reference line on lateral cephalograms to assess the mandibular diversion pattern, using Y-axis and the Frankfort mandibular plane angle (FMA). Stein$\mathrm{er}^{8}$ postulated Sella-Nasion to mandibular plane angle (SN.MP) to assess vertical growth pattern using the anterior cranial base as the reference plane. Schwartz, using the palatal plane, proposed the maxillary/mandibular planes angle (MMA) to assess intermaxillary relationship in the vertical dimension. Later, linear parameters, which included Jarabak's ratio and facial height ratio (LAFH.TAFH) were also used to assess the facial vertical growth of an individual. ${ }^{10}$

There are various linear and angular analyses for evaluating vertical skeletal growth of an individual. The commonly used angular analyses include Sella-Nasion to Gonion-Gnathion plane angle (SN.GoGn), Sella-Nasion to Gonion-Menton plane angle (SN.MP), Frankfort to mandibular plane angle (FMA), maxillary/mandibular planes angle (MMA) and Y-axis., ${ }^{7,8,9,11}$ The linear parameters used to determine vertical growth pattern include Jarabak's ratio and facial height ratio (LAFH.TAFH). ${ }^{10}$ A literature review showed that all of the aforementioned parameters have some shortcomings in terms of identifying the landmarks. ${ }^{12,13}$ Paranhos et $\mathrm{al},{ }^{12}$ in their study, reported the Y-axis to be inadequate to assess vertical dysplasia, as the position of Gnathion (Gn) varies with sagittal malocclusion. Similarly, FMA was considered to be less reliable, as landmarks forming the FH plane are difficult to identify. ${ }^{13}$ To overcome the aforementioned shortcomings, new cephalometric analyses, such as the R-angle, are still being introduced. ${ }^{14}$

Apart from potential errors in landmark identification, the cephalometric norms established by the previous studies may not serve adequately for other population groups. A survey of the pertinent literature also showed that variation within the norms may occur due to ethnic differences. Shaikh and Alvi, ${ }^{15}$ in their study on a sample of Pakistani population, showed a difference in facial height ratio, as compared to Caucasians. In contrast, another study reported a normal facial height of 50-55\% in Pakistani subjects. ${ }^{16}$ Because of these inherited discrepancies, the norms could only be used as a reference and not as absolute values.

Previously, many studies have reported the correlation between various skeletal analyses, ${ }^{17,18}$ but only a few have compared the diagnostic accuracy and the applicability of the various analyses. ${ }^{19}$ Moreover, during cephalometric analysis, certain cases present with a wide range of readings and not all the parameters used to assess vertical growth indicate a specific pattern. Hence, this study aimed to identify the skeletal analysis that performs best for the identification of vertical facial pattern in borderline cases. Thus, unnecessary analysis can be eliminated, leading to an efficient treatment plan.

\section{MATERIAL AND METHODS}

A cross sectional study was conducted with the data collected from the diagnostic records of patients visiting the dental clinics of the authors. Keeping a power of study $(\beta)$ as $80 \%, \alpha=0.05$, and using the correlation value $(r)=0.168$, as reported by Asad and Naeem, ${ }^{18}$ sample size was calculated to be 126 . This number was inflated by 10\%, which showed that we needed at least 135 subjects.

A total of 161 subjects (71 males and 90 females; mean age $=23.6 \pm 4.6$ years), aged between $18-35$ years old, having clear and good quality cephalograms, were included in the study, whereas those with a history of growth problems, trauma or previous orthodontic treatment were excluded. 


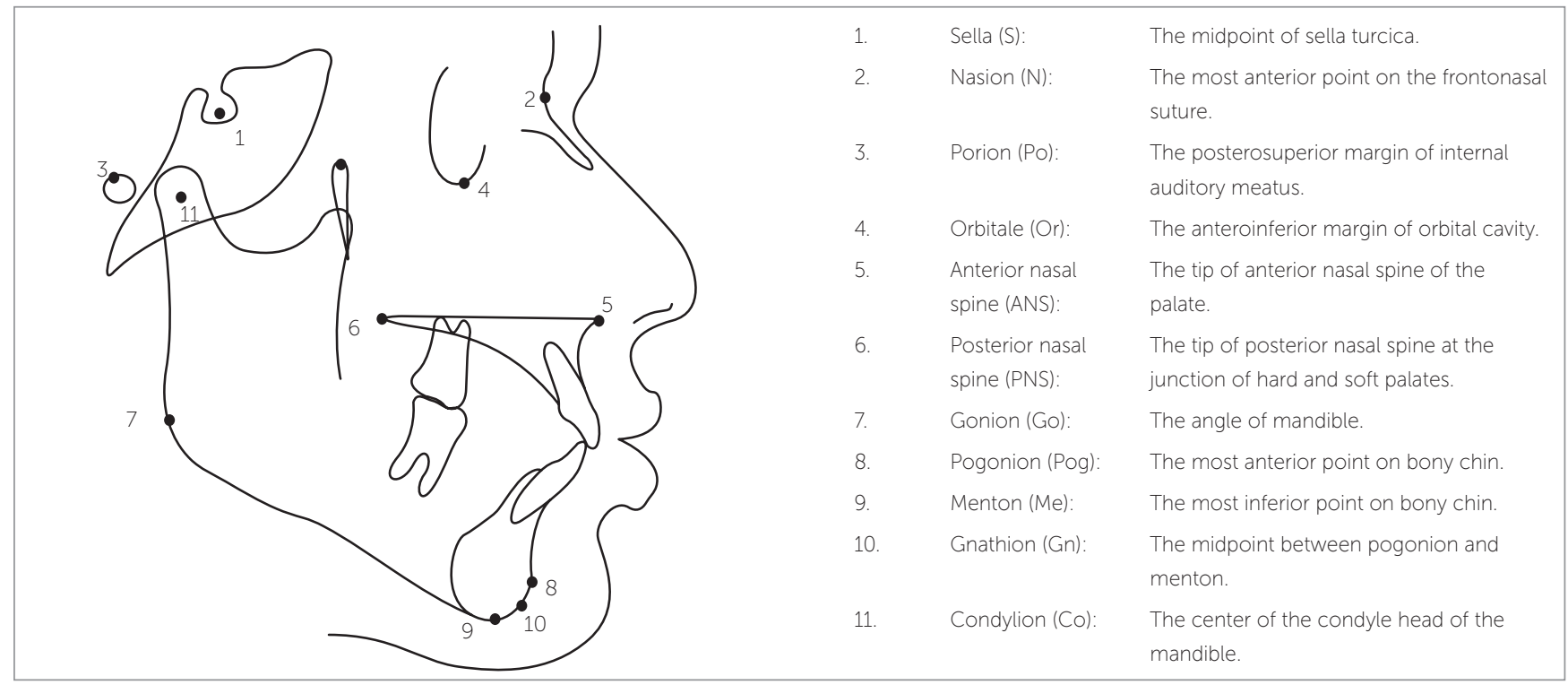

Figure 1 - Skeletal landmarks.

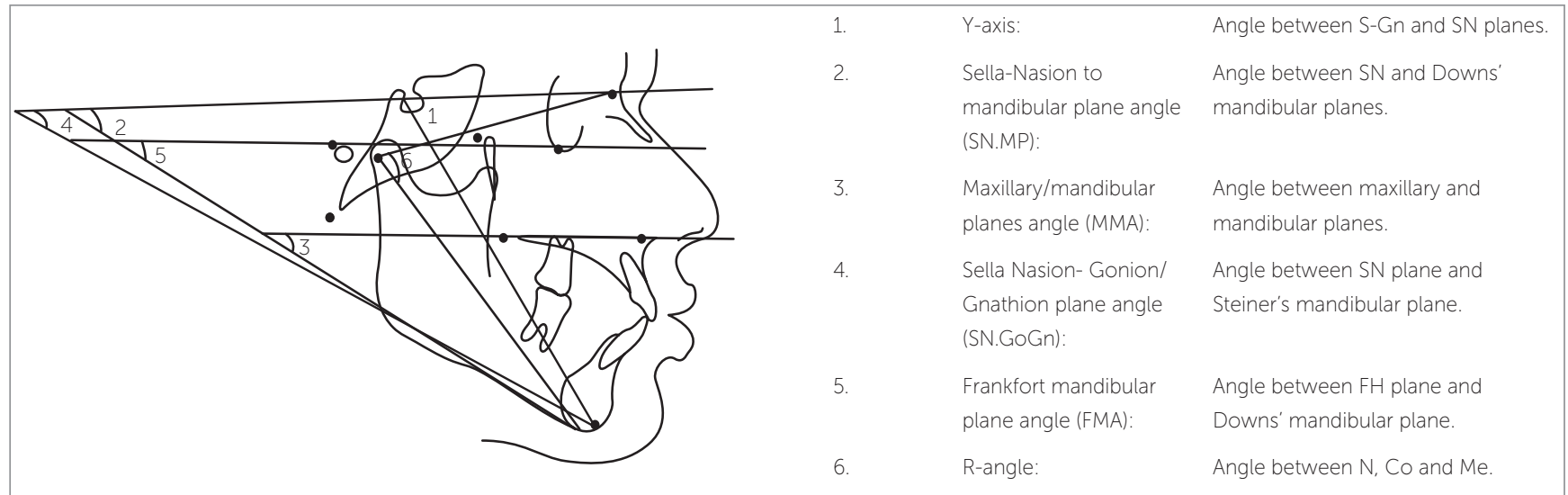

Figure 2 - Skeletal angular parameters.

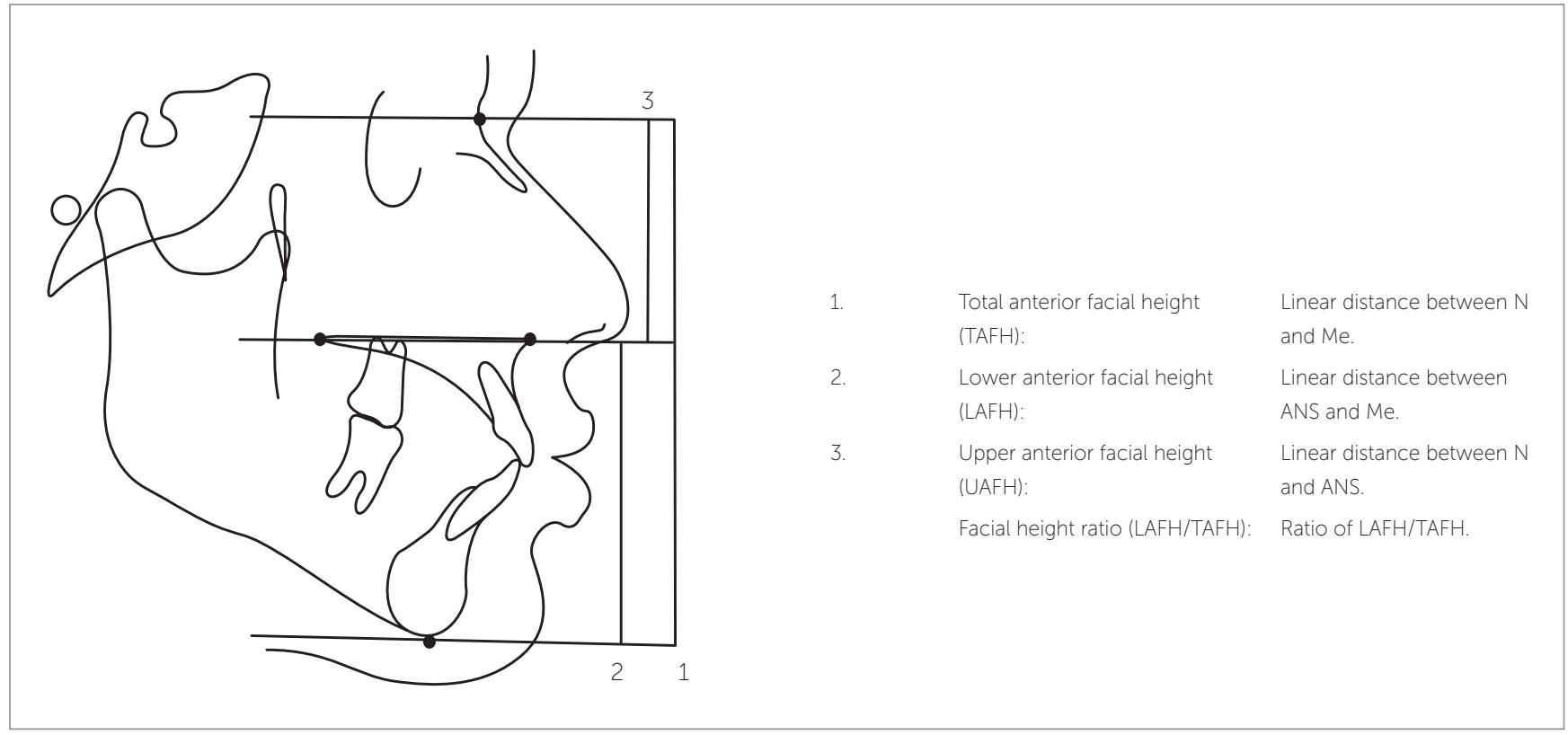

Figure 3 - Skeletal linear parameters. 
Pretreatment lateral cephalograms were used to evaluate vertical skeletal patterns. The distance from the imaging device to the midsagittal plane of the patient was kept constant at $60 \mathrm{~cm}$, and the distance from the film to the midsagittal plane was kept at $15 \mathrm{~cm}$. Cephalograms were traced by hand on matte acetate paper, with a $0.5-\mathrm{mm}$ lead pencil, over an illuminator, by the main investigator using the conventional method. Skeletal landmarks were identified (Fig 1). Measurements were taken with the help of a millimeter ruler and a protractor.

The angular parameters were measured as described bellow (Fig 2):

" Y-axis: The angle between S-Gn and SN planes.

" Sella-Nasion to mandibular plane angle (SN.MP): Angle between SN and Downs' mandibular planes.

" Maxillary/mandibular planes angle (MMA): The angle between maxillary and mandibular planes.

" Sella-Nasion to Gonion-Gnathion angle (SN.GoGn): The angle between $\mathrm{SN}$ and Steiner's mandibular planes.

» Frankfort mandibular plane angle (FMA): The angle between FH and Downs' mandibular plane.

» R-angle: The angle between N, Co and Me.

The skeletal linear parameters were the following (Fig 3):

» Total anterior facial height (TAFH): Linear distance between $\mathrm{N}$ and $\mathrm{M}$.

" Lower anterior facial height: (LAFH): Linear distance between ANS and Me.

» Facial height ratio (LAFH.TAFH): The ratio of LAFH/TAFH.

The cephalometric norms of each skeletal analysis previously established in the literature were used in the study (Table 1). On the basis of norms of each parameter, the subjects were labeled as hypodivergent, normodivergent and hyperdivergent. Nineteen subjects were shown to have the same facial pattern by all the parameters and thus were eliminated based on a clear-cut diagnosis. Each of the remaining 161 subjects had at least one cephalometric analysis giving conflicting diagnosis of the vertical facial pattern. The final diagnosis of vertical growth pattern of these subjects was based on the results of the majority of parameters, which enabled us to divide our sample into hypodivergent, normodivergent or hyperdivergent. Thus, the division of our sample resulted in the following groups:

" Low angle: 46.

" Normal angle: 66.

" High angle: 49.
The cases in which diagnosis of a particular cephalometric parameter matched the final diagnosis were regarded as the correctly diagnosed cases. The number of correctly diagnosed cases was used to assess the diagnostic performance of each of the cephalometric parameters.

To assess intraexaminer reliability, 30 radiographs were randomly selected and reanalyzed by the main investigator. The intraclass correlation coefficient denoted that the original and the repeated measurements showed a high correlation (Table 2).

Data were analyzed by means of SPSS for Windows (version 20.0, SPSS Inc. Chicago, USA). Various vertical skeletal parameters were correlated by means of Pearson Correlation. Correlations among various skeletal parameters were also determined separately for males and females. Kappa statistics was applied to assess the level of agreement between the diagnostic interpretation of cephalometric parameters and the final diagnosis made from the majority factor. Positive predictive value (PPV) and the sensitivity of each cephalometric analysis were calculated from the two-by-two tables. A $p$-value of $\leq 0.05$ was taken as statistically significant.

\section{RESULTS}

The sample consisted of 161 subjects that included 90 females (mean age $=24.65 \pm 4.08$ years) and 61 males (mean age $=22.48 \pm 4.89$ years). The subjects were divided into hypodivergent, normodivergent and hyperdivergent groups. The means and standard deviation of each cephalometric parameter are shown in Table 3. The groups were statistically matched on the basis of chronological age and sagittal relationship.

Pearson Correlation was used to determine the correlation between various skeletal analyses. A strong correlation was present between SN.GoGn and FMA $(\mathrm{r}=0.874)$, SN.GoGn and SN.MP $(\mathrm{r}=0.852)$, and SN.GoGn and MMA ( $\mathrm{r}=0.811)$. A moderate positive correlation was present between FMA and R-angle $(r=0.724)$, FMA and SN-GoMn $(\mathrm{r}=0.769)$, FMA and MMA $(\mathrm{r}=0.776)$ and $\mathrm{R}$-angle and MMA ( $\mathrm{r}=0.675)$ (Table 4).

Correlation was also determined for sex separately. A strong positive correlation was found between SN.GoGn and SN.MP for both males $(r=0.898)$ and females $(\mathrm{r}=0.806)$ (Tables 5 and 6). 
Table 1 - Cephalometric norms of skeletal analyses.

\begin{tabular}{|c|c|c|c|}
\hline Parameter & Hypodivergent & Normodivergent & Hyperdivergent \\
\hline SN.GoGn ${ }^{8}$ & $<28^{\circ}$ & $28^{\circ}-36^{\circ}$ & $>36^{\circ}$ \\
\hline $\mathrm{FMA}^{7}$ & $<21^{\circ}$ & $21^{\circ}-29^{\circ}$ & $>29^{\circ}$ \\
\hline$M^{M} A^{9}$ & $<21^{\circ}$ & $21^{\circ}-29^{\circ}$ & $>29^{\circ}$ \\
\hline Y-Axis ${ }^{8}$ & $<61^{\circ}$ & $61^{\circ}-68^{\circ}$ & $>68^{\circ}$ \\
\hline SN.MP7 & $<28^{\circ}$ & $28^{\circ}-36^{\circ}$ & $>36^{\circ}$ \\
\hline Facial height ratio (LAFH.TAFH) ${ }^{16}$ & $<50 \%$ & $50-55 \%$ & $>55 \%$ \\
\hline $\mathrm{R}_{\text {-angle }}{ }^{14}$ & $<70.5^{\circ}$ & $70.5^{\circ}-75.5^{\circ}$ & $>75.5^{\circ}$ \\
\hline
\end{tabular}

Table 2 - Intraclass correlation coefficient.

\begin{tabular}{|c|c|c|c|}
\hline Measurements & $\begin{array}{l}1^{\text {st }} \text { reading } \\
(n=30)\end{array}$ & $\begin{array}{l}2^{\text {nd }} \text { reading } \\
\qquad(n=30)\end{array}$ & ICC \\
\hline SN.GoGn & $28.90 \pm 8.49$ & $29.10 \pm 8.29$ & 0.997 \\
\hline FMA & $25.17 \pm 6.61$ & $25.33 \pm 6.33$ & 0.994 \\
\hline MMA & $21.63 \pm 5.98$ & $21.86 \pm 6.02$ & 0.996 \\
\hline Y-axis & $66.60 \pm 4.56$ & $66.66 \pm 4.59$ & 0.995 \\
\hline SN.MP & $27.83 \pm 7.07$ & $27.86 \pm 7.12$ & 0.997 \\
\hline ANS-Me & $68.10 \pm 6.68$ & $68.36 \pm 6.62$ & 0.997 \\
\hline $\mathrm{Na}-\mathrm{Me}$ & $52.51 \pm 3.71$ & $52.48 \pm 3.90$ & 0.990 \\
\hline R-angle & $72.53 \pm 4.06$ & $72.36 \pm 4.11$ & 0.994 \\
\hline
\end{tabular}

ICC: Intraclass correlation coefficient.

$n=30$.

Kappa statistics assessed the agreement among diagnostic criteria of various cephalometric analyses. A substantial agreement was present between SN.GoGn and the final group $(\mathrm{k}=0.850, p<0.01)$ (Table 7).

Positive predictive value (PPV) and sensitivity of each diagnostic parameter were also calculated for each group separately. In the hypodivergent group, MMA showed the highest sensitivity (0.934), whereas FMA showed the highest PPV (0.964). In the normodivergent group, FMA showed the highest sensitivity (0.909) and SN.GoGn had the highest PPV (0.903). SN.GoGn showed the highest sensitivity (0.980) and PPV (0.87) in the hyperdivergent group (Table 8).

\section{DISCUSSION}

In orthodontic diagnosis and treatment planning, it is essential to accurately assess an individual's facial skeletal pattern in all three dimensions, i.e. transverse, vertical and sagittal. The vertical facial pattern forms an important aspect in Orthodontics during the process of diagnosis and treatment planning by defining the variability in treatment planning, mechanics as well as in facial proportions. ${ }^{11}$ Tweed ${ }^{20}$ has related the stability of mandibular incisors after treatment based on vertical growth pattern. Since the vertical growth of face is the last to end, the assessment of facial discrepancy in the vertical dimension is not only important for an accurate diagnosis and an 
Table 3 - Mean value of cephalometric parameters

\begin{tabular}{|c|c|c|c|}
\hline Parameter & $\begin{array}{c}\text { Hypodivergent } \\
\qquad n=46 \\
\text { Means } \pm \text { SD }\end{array}$ & $\begin{array}{l}\text { Normodivergent } \\
n=66 \\
\text { Means } \pm \text { SD }\end{array}$ & $\begin{array}{l}\text { Hyperdivergent } \\
\qquad n=49 \\
\text { Means } \pm \text { SD }\end{array}$ \\
\hline SN.GoGn & $24.04 \pm 3.37$ & $31.43 \pm 3.74$ & $41.97 \pm 4.25$ \\
\hline FMA & $19.53 \pm 3.68$ & $25.98 \pm 3.27$ & $33.94 \pm 4.649$ \\
\hline MMA & $16.64 \pm 3.31$ & $22.44 \pm 3.12$ & $29.31 \pm 3.48$ \\
\hline Y-Axis & $59.33 \pm 3.25$ & $62.49 \pm 3.54$ & $67.06 \pm 5.54$ \\
\hline SN.MP & $23.75 \pm 3.82$ & $29.94 \pm 3.28$ & $38.16 \pm 4.45$ \\
\hline LAFH.TAFH & $50.46 \pm 2.21$ & $50.97 \pm 2.83$ & $52.26 \pm 3.37$ \\
\hline R-angle & $70.56 \pm 3.06$ & $74.43 \pm 2.92$ & $80.00 \pm 3.61$ \\
\hline
\end{tabular}

SD: standard deviation

$n=161$.

Table 4 - Correlation among various skeletal analyses to assess vertical growth pattern.

\begin{tabular}{|c|c|c|c|c|c|c|c|}
\hline & $Y$-axis & FMA & SN.GoGn & R-angle & SN.MP & MMA & LAFH.TAFH \\
\hline Y-axis & 1 & $0.592^{* *}$ & $0.595^{\star *}$ & $0.622^{* *}$ & $0.489 * *$ & $0.475^{* *}$ & -0.033 \\
\hline FMA & & 1 & $0.874^{\star *}$ & $0.724^{* *}$ & $0.769 * *$ & $0.776^{\star *}$ & $0.208^{* *}$ \\
\hline SN.GoGn & & & 1 & $0.776^{\star *}$ & $0.852^{* *}$ & $0.818^{* \star}$ & $0.222^{* *}$ \\
\hline R-angle & & & & 1 & $0.678^{* *}$ & $0.675^{\star *}$ & $0.243^{\star *}$ \\
\hline SN.MP & & & & & 1 & $0.811^{\star \star}$ & 0.131 \\
\hline MMA & & & & & & 1 & $0.179 *$ \\
\hline LAFH.TAFH & & & & & & & 1 \\
\hline
\end{tabular}

$n=161$; Pearson correlation: weak correlation $( \pm 0.01<r< \pm 0.5)$; moderate correlation $( \pm 0.5<r< \pm 0.8)$; strong correlation $( \pm 0.8<r< \pm 1)$. ${ }^{*} p<0.05$; $* * p<0.01$.

Table 5 - Correlation among various skeletal analyses to assess vertical growth pattern in males.

\begin{tabular}{|c|c|c|c|c|c|c|c|}
\hline & Y-axis & FMA & SN.GoGn & R-angle & SN.MP & MMA & LAFH.TAFH \\
\hline Y-axis & 1 & $0.634^{* *}$ & $0.644^{\star *}$ & $0.670 * *$ & $0.658^{* *}$ & $0.570 * *$ & -0.144 \\
\hline FMA & & 1 & $0.901^{* *}$ & $0.802^{\star *}$ & $0.862^{* *}$ & $0.877^{\star *}$ & $0.298^{*}$ \\
\hline SN.GoGn & & & 1 & $0.821^{\star *}$ & $0.898^{* *}$ & $0.854^{* *}$ & $0.260^{*}$ \\
\hline R-angle & & & & 1 & $0.779 * *$ & $0.720 * *$ & $0.292^{*}$ \\
\hline SN.MP & & & & & 1 & $0.875^{\star * *}$ & 0.232 \\
\hline MMA & & & & & & 1 & 0.217 \\
\hline LAFH.TAFH & & & & & & & 1 \\
\hline
\end{tabular}

$n=71$; Pearson correlation: weak correlation $( \pm 0.01<r< \pm 0.5)$; moderate correlation $( \pm 0.5<r< \pm 0.8)$; strong correlation $( \pm 0.8<r< \pm 1)$. ${ }^{\star} p<0.05$; ${ }^{\star} \star p<0.01$.

Table 6 - Correlation among various skeletal analyses to assess vertical growth pattern in females.

\begin{tabular}{|c|c|c|c|c|c|c|c|}
\hline & Y-axis & FMA & SN.GoGn & $\mathbf{R}$-angle & SN.MP & MMA & LAFH.TAFH \\
\hline$Y$-axis & 1 & $0.585^{\star *}$ & $0.570 * *$ & $0.599 * *$ & $0.376^{\star *}$ & $0.419 * *$ & 0.050 \\
\hline FMA & & 1 & $0.850^{* *}$ & $0.669 * *$ & $0.657^{\star *}$ & $0.640^{\star *}$ & 0.119 \\
\hline SN.GoGn & & & 1 & $0.744^{* *}$ & $0.806^{* *}$ & $0.782^{\star *}$ & 0.190 \\
\hline R-angle & & & & 1 & $0.604^{* *}$ & $0.650 * *$ & 0.187 \\
\hline SN.MP & & & & & 1 & $0.736^{\star *}$ & 0.041 \\
\hline MMA & & & & & & 1 & 0.148 \\
\hline LAFH.TAFH & & & & & & & 1 \\
\hline
\end{tabular}

$n=90$; Pearson correlation: weak correlation $( \pm 0.01<r< \pm 0.5)$; moderate correlation $( \pm 0.5<r< \pm 0.8)$; strong correlation $( \pm 0.8<r< \pm 1) .{ }^{*} p<0.05 ;{ }^{* *} p<0.01$. 
Table 7 - Assessment of agreement among diagnositic criteria of skeletal analyses.

\begin{tabular}{|c|c|c|c|c|c|}
\hline \multirow[t]{2}{*}{ Parameter } & \multirow{2}{*}{$\begin{array}{l}\text { Hypodivergent } \\
\qquad n=46\end{array}$} & \multirow{2}{*}{$\begin{array}{l}\text { Normodivergent } \\
\qquad n=66\end{array}$} & \multirow{2}{*}{$\begin{array}{l}\text { Hyperdivergent } \\
\qquad n=49\end{array}$} & \multicolumn{2}{|c|}{$n=161$} \\
\hline & & & & Kappa & P-value \\
\hline SNGoGn & 49 & 62 & 50 & $0.850 * *$ & 0.000 \\
\hline MMA & 58 & 77 & 26 & $0.590 * *$ & 0.000 \\
\hline YAxis & 110 & 42 & 9 & $0.152^{\star \star}$ & 0.001 \\
\hline FMA & 28 & 84 & 49 & $0.711^{\star *}$ & 0.000 \\
\hline SNGoMn & 54 & 72 & 25 & $0.639 * *$ & 0.000 \\
\hline LAFH/TAFH & 50 & 87 & 24 & $0.046^{*}$ & 0.0401 \\
\hline R-Angle & 28 & 74 & 59 & $0.561^{* *}$ & 0.000 \\
\hline
\end{tabular}

$\mathrm{n}=161 ;$ Kappa Statistics.

Table 8 - Assessment of agreement among diagnostic criteria of skeletal analyses.

\begin{tabular}{|c|c|c|c|c|c|c|c|c|c|}
\hline \multirow[t]{2}{*}{ Parameter } & \multicolumn{3}{|c|}{ Hypodivergent ( $n=46$ ) } & \multicolumn{3}{|c|}{ Normodivergent $(n=66)$} & \multicolumn{3}{|c|}{ Hyperdivergent ( $n=49)$} \\
\hline & $\begin{array}{l}\text { Correctly } \\
\text { diagnosed } \\
\text { cases }\end{array}$ & $\begin{array}{c}\text { Positive } \\
\text { predictive } \\
\text { value }\end{array}$ & Sensitivity & $\begin{array}{l}\text { Correctly } \\
\text { diagnosed } \\
\text { cases }\end{array}$ & $\begin{array}{l}\text { Positive } \\
\text { predictive } \\
\text { value }\end{array}$ & Sensitivity & $\begin{array}{l}\text { Correctly } \\
\text { diagnosed } \\
\text { cases }\end{array}$ & $\begin{array}{c}\text { Positive } \\
\text { predictive } \\
\text { value }\end{array}$ & Sensitivity \\
\hline SN.GoGn & 40 & 0.816 & 0.869 & 56 & 0.903 & 0.848 & 43 & 0.980 & 0.871 \\
\hline MMA & 43 & 0.741 & 0.934 & 50 & 0.649 & 0.757 & 26 & 0.961 & 0.530 \\
\hline Y-axis & 42 & 0.381 & 0.913 & 18 & 0.428 & 0.272 & 11 & 0.888 & 0.224 \\
\hline FMA & 27 & 0.964 & 0.586 & 60 & 0.714 & 0.909 & 44 & 0.897 & 0.897 \\
\hline SN-GoMn & 41 & 0.914 & 0.891 & 50 & 0.694 & 0.757 & 32 & 0.914 & 0.653 \\
\hline $\mathrm{LAFH} / \mathrm{TAFH}$ & 11 & 0.222 & 0.239 & 39 & 0.649 & 0.590 & 8 & 0.961 & 0.163 \\
\hline R-angle & 25 & 0.892 & 0.50 & 47 & 0.648 & 0.712 & 40 & 0.711 & 0.816 \\
\hline
\end{tabular}

Positive predictive value; Sensitivity. $n=161$.

efficient treatment planning, it is of utmost significance to prevent relapse after the corrected malocclusion.

There are various skeletal parameters used to assess the vertical growth pattern of an individual. A multitude of times different parameters show conflicting results, and a specific diagnosis is hard to reach. Hence, this study focused on evaluating the diagnostic accuracy of various parameters so that the process of diagnosis may be limited to a minimal number of analyses.

In the present study, a final diagnosis of vertical growth pattern was made on the basis of the results of the majority of analyses. The results of this final diagnosis were treated as the gold standard and were used to compare the diagnostic performance of the seven analyses using sensitivity, positive predictive value as well as Kappa statistics. The groups statistically matched well on the basis of age and sagittal patterns.

Correlation between various skeletal parameters has already been reported in the literature. ${ }^{17,18,19}$ In our study, all skeletal analyses showed a significant correlation with each other. A strong correlation was present between SN.GoGn and all the other skeletal analyses, except facial height ratio (LAFH.TAFH). MMA showed a moderate correlation with other skeletal analyses. Our results are in concordance with another study conducted by Asad and Naeem. ${ }^{18}$

SN.MP and SN.GoGn showed a strong correlation in both males $(\mathrm{r}=0.898, p<0.01)$ and females $(\mathrm{r}=0.806)$. In contrast, Bahrou et $\mathrm{al}^{17}$ reported a moderate correlation between MMA and facial height ratio (LAFH.TAFH) in males $(r=0.550)$ and females $(\mathrm{r}=0.497)$. The heterogeneity in results might be due to a difference in sample size. It is worth mentioning that any value of correlation does not relate to the diagnostic accuracy of any analysis.

Hence, in the present study, to compare the diagnostic agreement between skeletal analyses and the final diagnosis, Kappa statistics was applied. A substantial 
agreement was present between SN.GoGn and the final group $(\mathrm{k}=0.850)$. Kappa statistics accounts whether a certain parameter indicates a specific vertical pattern simply by chance and provides more information than a simple correlation between two parameters. ${ }^{21}$

To evaluate validity of diagnostic indicators in identifying the vertical skeletal pattern, sensitivity was also calculated in each group separately. MMA showed a high sensitivity in the hypodivergent group (0.934), whereas FMA showed the highest sensitivity in normodivergent (0.909) and hyperdivergent groups (0.897).

To further clarify whether a certain parameter can truly diagnose the vertical pattern, this study reports the positive predictive values (PPV) of all cephalometric parameters used in the present study. FMA yielded the highest PPV in the hypodivergent group (0.964), whereas SN.GoGn yielded the highest PPV in normodivergent (0.903) and hyperdivergent (0.897) groups. Thus, despite lesser sensitivity values, FMA and SN.GoGn proved to be more valid indicators in determining vertical skeletal pattern.

Multiple parameters can be used to evaluate the vertical growth pattern of an individual. In the present study, only the analyses commonly used during orthodontic diagnosis, indicating a specific growth pattern of the jaws in reference to the cranial base, were included. Other analyses, such as facial axis and facial depth angle, were excluded, as they indicate only chin position with respect to the cranial base. ${ }^{22}$ As new parameters are being proposed, analyses, such as R-angle, were also included in the study to check their reliability against commonly used analyses. ${ }^{14}$
With advances in digital imaging and tridimensional (3D) imaging technique, using the twodimensional imaging technique (lateral cephalogram) to evaluate skeletal jaw relationship may be a potential limitation of this study. ${ }^{23,24} \mathrm{~A}$ survey of the current literature showed that although CBCTgenerated images are better at evaluating skeletal jaw discrepancy, manual and digital lateral cephalograms are still reliable and valid for scientific research with the added advantage of a lower radiation dose..$^{25,26,27}$

\section{CONCLUSIONS}

1. A strong correlation was found between SN.GoGn and other skeletal vertical analyses, except facial height ratio (LAFH.TAFH).

2. SN.GoGn and FMA were found to be the most reliable indicators in assessing facial vertical growth pattern.

3. Facial height ratio (LAFH.TAFH) was found to be the least reliable indicator in assessing facial vertical growth pattern.

Hence, the number of cephalometric analyses to evaluate vertical skeletal jaw discrepancy may be reduced to a few analyses with higher diagnostic performance. This may result in accurate diagnosis and efficient treatment plan based on an individual's facial soft tissue pattern.

\section{Acknowledgements}

The authors would like to thank Dr. Waqar Jeelani for his assistance in study methodology and statistical analyses. 


\section{REFERENCES}

1. Janson GR, Metaxas A, Woodside DG. Variation in maxillary and mandibular molar and incisor vertical dimension in 12-year-old subjects with excess, normal, and short lower anterior face height. Am J Orthod Dentofacial Orthop. 1994 Oct;106(4):409-18

2. Schendel SA, Eisenfeld J, Bell WH, Epker BN, Mishelevich DJ. The long face syndrome: vertical maxillary excess. Am J Orthod. 1976 Oct;70(4):398-408

3. Opdebeeck H, Bell WH. The short face syndrome. Am J Orthod. 1978 May:73(5):499-511

4. Bishara SE, Jakobsen JR. Changes in overbite and face height from 5 to 45 years of age in normal subjects. Angle Orthod. 1998 Jun;68(3):209-16

5. Enoki C, Telles CS, Matsumoto MA. Dental-skeletal dimensions in growing individuals with variations in the lower facial height. Braz Dent J. 2004;15(1):68-74

6. Cook AH, Sellke TA, BeGole EA. Control of the vertical dimension in Class II correction using a cervical headgear and lower utility arch in growing patients. Part I. Am J Orthod Dentofacial Orthop. 1994 Oct;106(4):376-88.

7. Downs WB. Variations in facial relationships; their significance in treatment and prognosis. Am J Orthod. 1948 Oct; 34(10):812-40.

8. Steiner CC. Cephalometrics for you and me. Am J Orthod. 1953 Oct;39(10):720-55.

9. Schwartz AM. Roentgenostatics. Am J Orthod. 1961 Aug:47(8):561-85.

10. Horn AJ. Facial Height Index. Am J Orthod Dentofacial Orthop. 1992 Aug:102(2):180-6

11. Ricketts RM. Planning treatment on the basis of the facial pattern and an estimate of its growth. Angle Orthod. 1957 Jan;27(1):14-37.

12. Paranhos LR, Brando TM, Kaieda AK, Ramos AL, Torres FC. The inadequacy of the Y-axis of growth (SNGn) for the vertical pattern assessment in patients with sagittal discrepancies. J Contemp Dent Pract. 2014 Mar 1;15(2):169-73.

13. Jacobson A. Radiographic cephalometry. How reliable is cephalometric prediction? Chicago: Quintessence; 1995

14. Rizwan M, Mascarenhas R. A new parameter for assessing vertical skeletal discrepancies: the R angle. Rev Latinoam Ortodon Odontop. 2013 June:16:1-7.

15. Shaikh AJ, Alvi AR. Comparison of cephalometric norms of esthetically pleasing faces. J Coll Physicians Surg Pak. 2009 Dec:19(12):754-8.
16. Sukhia H, Sukhia RH. Lower facial height treatment changes in bi-maxillary protrusion orthodontic cases. Pak Oral Dent J. 2013 Apr:33(1):65-70

17. Bahrou S, Hassan AA, Khalil F. Facial proportions in different mandibular rotations in Class I individuals. Int Arab J Dent. 2014;5(1):9-18

18. Asad S, Naeem S. Correlation between various vertical dysplasia assessment parameters. Pak Oral Dent J. 2009 Dec:1(2):28-33.

19. Rizwan M, Mascarenhas R, Hussain A. Reliability of the existing vertical dysplasia indicators in assessing a definitive growth pattern. Rev Latinoam Ortodon Odontop. 2011 Dec:16:1-5

20. Tweed $\mathrm{CH}$. The Frankfort-mandibular plane angle in orthodontic diagnosis classification, treatment planning, and prognosis. Am J Orthod Oral Surg. 1946 Apr;32:175-230

21. Viera AJ, Garrett JM. Understanding interobserver agreement: the kappa statistic Fam Med. 2005 May:37(5):360-3.

22. Ricketts RM. Cephalometric analysis and synthesis. Angle Orthod 1961 July:31(3):141-56

23. Kusnoto B, Kaur P, Salem A, Zhang Z, Galang-Boquiren MT, Viana G, et al. Implementation of ultra-low-dose $\mathrm{CBCT}$ for routine $2 \mathrm{D}$ orthodontic diagnostic radiographs: Cephalometric landmark identification and image quality assessment. Semin Orthod. 2015;21(4):233-47.

24. Park JH, Tai K, Owtad P. 3-Dimensional cone-beam computed tomography superimposition: a review. Semin Orthod. 2015 Dec;21(4):263-73.

25. Huerta JVR, Sosa JGO, Ledesma AF. Comparative study between cone-beam and digital lateral head film cephalometric measurements. Rev Mex Ortodon. 2015 Apr-Jun;3(2):84-7.

26. Navarro RL, Oltramari-Navarro PV, Fernandes TM, Oliveira GF, Conti AC, Almeida MR, et al. Comparison of manual, digital and lateral CBCT cephalometric analyses. J Appl Oral Sci. 2013 Mar-Apr;21(2):167-76.

27. Cassetta M, Altieri F, Di Giorgio R, Silvestri A. Two-dimensional and three-dimensional cephalometry using cone beam computed tomography scans. J Craniofac Surg. 2015 Jun;26(4):e311-5. 